R E S E $\tilde{N}$ A S

\title{
El buen hacer en educación. Narrativas contrahegemónicas y prácticas inclusivas
}

\author{
Mayka García García*
}

Recibido: 9 de septiembre de 2020 Aceptado: 10 de septiembre de 2020 Publicado: 30 de septiembre de 2020

To cite this article: García, M. (2020). Reseña de Gallego Noche, B. (2019). El buen hacer en educación. Narrativas contrahegemónicas y prácticas inclusivas. Cádiz: Servicio de Publicaciones de la Universidad de Cádiz. Márgenes, Revista de Educación de la Universidad de Málaga, 1 (3), 390-392

DOI: https://dx.10.24310/mgnmar.v1i3.10170

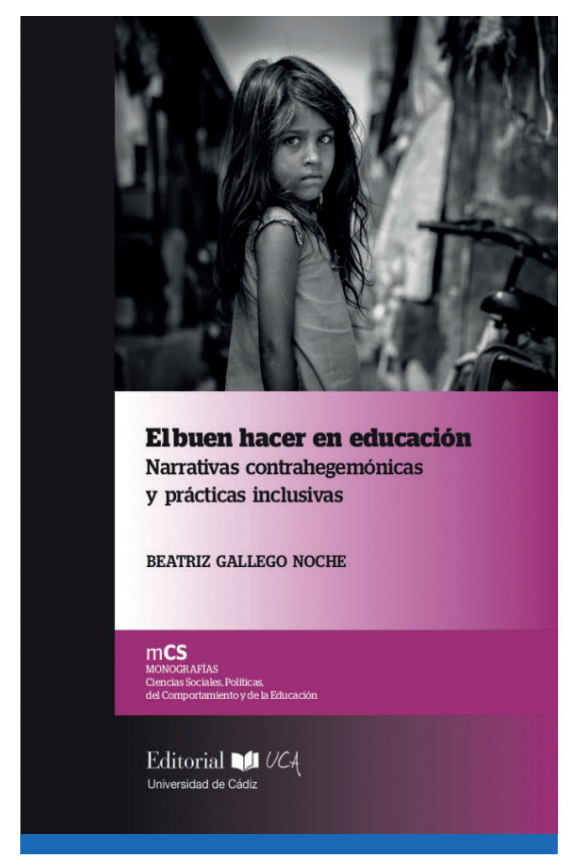

El buen hacer en educación. Narrativas contrahegemónicas y prácticas inclusivas. Gallego Noche, B. (2019). Cádiz: Servicio de Publicaciones de la Universidad de Cádiz, pp. 164. ISBN: 978-84-9828-764-6

\section{RESUMEN}

Esta obra es, en esencia, una propuesta de resignificación de la práctica educativa inclusiva a partir a un trabajo de comprensión profunda de las claves que nos interpelan en una crisis global que sostienen la exclusión. La mirada eco-feminista, interseccional y humanista impregna los análisis que abren un nuevo espacio para el buen hacer en educación, desde una perspectiva decolonial que pasa por la politización del curriculum en claves críticas.

Palabras clave: inclusión; currículum; bien común

Hace algunos años que en el ámbito de la educación inclusiva venimos reclamando la necesidad de resituar su objeto de estudio, construyendo una narrativa que nos ayude a acompañar nuestra práctica, porque hoy nos pensamos desde otros lugares enriquecidos de historias y fuentes diversas. El texto El Buen hacer en Educación. Narrativas contrahegemónicas y prácticas inclusivas es una obra que apunta es esa dirección, y que se edita en la colección de monografías de Ciencias Sociales, Políticas, del Comportamiento y de la Educación del sello editorial de la Universidad de Cádiz.

En sus primeras páginas, su autora nos muestra ese lugar conceptualmente autobiográfico desde el que vive la narración a la que denomina posición de partida, que invita a imaginar el mundo que cada cual habita, individual y colectivamente. Se trata de un trabajo eminentemente político, que trascurre entrelazando cuestiones filosóficas, sociológicas y pedagógicas. Asume que en este acto de esperanza que supone imaginar un mundo cualitativamente distinto 
y esencialmente humanizado, la educación -la buena educación- cobra especial sentido. Para acercarnos a esta buena educación, en primer lugar, se nos desgrana la delimitación del problema o, más bien problemas, que nos invitan a la reflexión y los marcos conceptuales que nos pueden ayudar a pensar alternativas. En segundo lugar, y desde lo anterior como sustento analizado de manera crítica, se resignifica la práctica educativa y se ofrecen propuestas de acción que vectorizan interseccionalmente desde la inclusión a la que se toma como eje.

Las lectoras y lectores de este libro, van encontrar en el primer capítulo, distintas imágenes que, muy de cerca, es decir apoyada en datos actuales, no sitúan ante la crisis global a la que nos enfrentamos como sociedad del siglo XXI. ¿Qué focos sostienen y perpetúan una sociedad excluyente y en crisis como la nuestra? La autora centra la mirada en tres dimensiones de la misma para recordarnos que esta nos interpela: la socioecológica, la de cuidados, y la de vulnerabilidad de la infancia. En torno a ellas se presenta una visión sistémica e interactiva que se asienta en la ética desde la que se construye cada foco, siendo la emoción un elemento constante y presente en el análisis de cada uno de estos.

Si el primer capítulo se conforma como el marco contextual, el segundo podría denominarse foco conceptual, donde fluyen teorías completas que proporcionan claves para la comprensión del ecofeminismo, de la Teoría de la acción comunicativa, de la perspectiva decolonial o de distintos enfoques de la justifica social, específicamente de las aportaciones Marta Nussbaum y de Amartya Sen. A través del mismo se narran las bases que sustentarán, más adelante, propuestas que pueden iluminar el abordaje de los problemas descritos desde aportaciones de naturaleza contrahegemónica, las cuales evidencian la necesidad de comprender la esencia de la deshumanización, siguiendo a Fanon. Denomina a las mismas claves de bóveda y sobre ellas articula distintas narraciones que, en realidad, suponen una teoría propia. En ella emerge una pedagogía de la vida que se sustenta en la eco-dependencia, la interdependencia y el cuidado, en el reconocimiento del sujeto y del nos-otras o nos-otras en la convivencia, lo que nos recuerda a las aportaciones de Humberto Maturana.

El capítulo tercero supone la transición hacía la acción, y en el mismo se resitúa la práctica educativa, una práctica de libertad que, orientada desde las propias experiencias de desigualdad subjetivizadas, pasan por la toma de conciencia de la opresión, con claras influencias freineanas. Por ello, para la autora, resignificar la práctica educativa supone, en esencia "un abordaje inclusivo, socio crítico y humanista de la práctica educativa: más allá de la constatación de la diferencia hay que poner de relieve las relaciones de poder entre los grupos, la situación de desventaja de una parte de ellos y su poder para cambiarlas (Gallego, 2019, p.107). En este resituar la práctica nos habla, entre otros asuntos, del sujeto, de la singularidad, de la necesitar de generar espacios para hacer emerger las voces, lo que nos recuerda a la justicia currricular de Connell, con la particularidad de tomar la interseccionalidad como eje natural para abordar la comprensión de las desigualdades.

¿Qué rasgos definirían una práctica educativa inclusiva? Es la cuestión hacia la que apunta el cuarto capítulo que anuncia la necesidad de un replanteamiento del currículum que posibilite transitar desde la exclusión a la inclusión. El buen hacer en educación era definido, en esencia, como una práctica necesariamente inclusiva en su acepción más política. Así pues, la práctica 


\section{R E S E $\widetilde{N}$ A S}

educativa inclusiva se visualiza como un rizoma en el que confluyen y se entrelazan las claves que se han ido desgranando en los capítulos anteriores. La incorporación de la ética que aporta la ecológica social y los valores como sustento, la redefinición de la relación con la naturaleza y las formas educativas de aproximarnos a su conocimiento desde principios de acción basados en el reconocimiento, la comunicación, la participación democrática, la concepción social del amor, la necesidad de cuidado y apoyo mutuo en la que emerge la solidaridad o la igualdad de género, son algunas de las claves desde las que se propone ese buen hacer.

Esta obra es un ejercicio de desconstrucción de las epistemologías dominantes que se dirige hacia una pedagogía disidente en cuyo horizonte se encuentra la dignidad, la equidad y la justicia social. Ello abre la posibilidad de resituar las prácticas inclusivas más allá de los debates tradicionales para construirlas a partir de una comprensión crítica y humanista centrada en la relación -en sus distintas vertientes- desde los sujetos, los contextos y para ellos, de hecho, para el bien común.

\section{REFERENCIAS}

Gallego Noche, B. (2019). El buen hacer en educación. Narrativas contrahegemónicas y prácticas inclusivas. España: Servicio de Publicaciones de la Universidad de Cádiz. 